\title{
Análise dos componentes do rendimento de diferentes cultivares de soja em Cachoeira do Sul
}

\author{
Analysis of components of the yield of different soy's cultivars at Cachoeira do Sul \\ Clarissa Moraes da Silva ${ }^{1}$; Zanandra Boff Oliveira ${ }^{2}$; Alberto Eduardo Knies ${ }^{3}$; Irajá Jantsch de Souza ${ }^{4}$ e \\ Tiago Tondolo Link ${ }^{5}$
}

\author{
1,2,4,5 Universidade Federal de Santa Maria, Campus Cachoeira do Sul. Cachoeira do Sul, Brasil \\ clarissamoraes37@outlook.com; zanandraboff@gmail.com; iraja_14@yahoo.com.br; tiagotondololink@hotmail.com
}

${ }^{3}$ Universidade Estadual do Rio Grande do Sul, Campus Cachoeira do Sul. Cachoeira do Sul, Brasil albertoek@gmail.com

\section{Resumo}

A cultura da soja é importante socioeconomicamente para o municipio de Cachoeira do Sul. O presente trabalho objetivou avaliar os componentes do rendimento e o rendimento de grãos de diferentes cultivares de soja irrigadas por aspersão no município. Foi realizado um experimento de campo. Os tratamentos constituiram de 3 cultivares: BMX GARRA; NS 4823; NS 5445; em 12 repetições, no delineamento experimental inteiramente casualizado. Foram realizadas avaliações morfológicas das plantas (índice de área foliar - IAF - e altura). Foi analisado os componentes do rendimento: número de vagens planta ${ }^{-1}$; número de grãos vagem ${ }^{-1}$; peso de mil grãos e rendimento de grãos $\left(\mathrm{kg} \mathrm{ha}^{-1}\right)$. A irrigação suplementar foi necessária para a manutenção da disponibilidade hidrica no solo à cultura, tendo em vista aos baixos volumes de precipitação pluviométrica durante o ciclo $(354 \mathrm{~mm})$ que foi inferior a evapotranspiração da cultura (467 mm). Diferenças estatísticas entre as cultivares foram observadas, destacando-se a cultivar BMX GARRA que apresentou IAF e altura de plantas maiores em comparação as demais cultivares. Esses resultados impactaram que a cultivar BMX GARRA

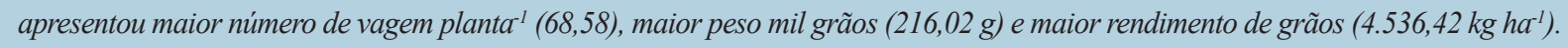

Palavras-chave: Grãos; Irrigação; Produtividade

\section{Abstract}

Soy is socio-economically important to the county of Cachoeira do Sul. The present work meant to evaluate the components of the yield and the yield of grains of different soy's cultivars sprinkler irrigated at the city. A field's experiment with seeding was made in 19/11/17. The treatments were constituted of 3 cultivars: BMX GARRA; NS 4823; NS 5445; in 12 repetitions, in the entirely casualized trial design. Morphological evaluations were performed on the plants (leaf area index - LAI and height). The yield's components were analyzed: number of string bean plants ${ }^{-1}$; number of string bean grains ${ }^{-1}$; weight of a thousand grains and yield of the grains $\left(\mathrm{kg} \mathrm{ha}^{-1}\right)$. Supplementary irrigation was necessary to maintain the soil water availability to the crop, due to the low rainfall during the cycle $(354 \mathrm{~mm})$, which was lower than the crop evapotranspiration $(467 \mathrm{~mm})$. Statistical differences between the cultivars were perceived, highlighting the BMX GARRA cultivar, that presented LAI and higher plants 'height in comparison to the other cultivars. These results impacted that the BMX GARRA cultivar presented a higher number of string bean plants ${ }^{-1}$ (68.58), a higher weight of a thousand grains (216.02g) and a higher yield of the grains $\left(4,536.42 \mathrm{~kg} \mathrm{ha}^{-1}\right)$. 


\section{Introdução}

A soja (Glycine max), pertence à família Fabaceae, é a principal fonte de óleo vegetal do mundo (STRECK et al., 2008). A cultura ocupa posição de destaque na modernização da agricultura brasileira, pois em menos de meio século, tecnologias especialmente desenvolvidas e apropriadas às condições brasileiras, revolucionaram totalmente os sistemas de produção e o Brasil passou de importador para maior exportador mundial de soja, principalmente pelos ganhos expressivos de produtividade (ZANON et al., 2018). Devido à importância econômica dessa cultura para o Brasil e para o estado do Rio Grande do Sul novas cultivares de soja são lançadas anualmente. Estudos básicos devem ser realizados de forma constante para auxiliar extensionistas e consultores a entenderem melhor os aspectos relacionados ao crescimento e ao desenvolvimento dessas novas cultivares (VERNETTI e VERNETTI JUNIOR, 2009).

No estado do Rio Grande do Sul, na safra 2016/17, a soja foi cultivada em 5,5 milhões de hectares, ou seja, em 73 \% das áreas cultivadas com grãos no período primavera/verão, resultando em uma produtividade média de 16,8 milhões de toneladas (EMATER, 2017). Destacando-se o município de Cachoeira do Sul, como segundo maior produtor do grão no estado, com uma área cultivada de 142,7 mil hectares, produzindo aproximadamente 390 mil toneladas (EMATER,2017, 2017).

De acordo com Zanon et al. (2018), dentre os fatores inerentes à produção agrícola, o clima continua aparecendo como aquele de mais difícil controle e maior ação sobre a limitação às máximas produtividades. Aliado a isto, a imprevisibilidade das variabilidades do clima confere à ocorrência de adversidades climáticas o principal fator de risco e de insucesso na exploração da cultura da soja. Matzenauer et al. (2003), estudando a estimativa do consumo relativo de água para a cultura da soja no Estado do Rio Grande do Sul, observaram que é frequente a ocorrência de deficiência hídrica durante o período crítico da soja, podendo-se esperar uma redução de rendimento de grãos de soja em nove a cada vinte safras, corroborando com as afirmativas anteriores.

No atual cenário da sojicultora, onde há cultivares adaptadas para as principais regiões produtoras no Brasil, a busca dos programas de melhoramento é por cultivares que apresentem maior potencial de produtividade e/ou resistência a fatores que impactem de forma negativa na produtividade (ZANON et al., 2018). O desenvolvimento e o crescimento são influenciados por fatores genéticos (tipo de crescimento, grupo de maturidade relativa e presença do gene da juvenilidade), climáticos (fotoperíodo, radiação solar, temperatura e disponibilidade de água) e de manejo (época de semeadura e características físico-químicas do solo), sendo que as interações desses fatores definem o potencial produtivo de cada cultivar e local de cultivo da soja (PIRES et al., 2005).

A produtividade de grãos é uma variável complexa, que expressa a interação da genética com o ambiente e está diretamente relacionada a práticas de manejo, que podem, ou não, potencializá-la. Devido a essa complexidade, esta pode ser subdividida em componentes de produtividade (ZANON et al., 2018). O conhecimento das respostas dos componentes do rendimento da planta de soja à disponibilidade de fotoassimilados e a identificação do momento em que estes componentes são formados são importantes na seleção de características a serem incorporados nos genótipos (BOARD e TAN, 1995).

Neste contexto, o objetivo deste estudo foi o de avaliar os componentes do rendimento e o rendimento de grãos de diferentes cultivares de soja irrigadas por aspersão em Cachoeira do Sul. 


\section{Materiais e métodos}

Foi instalado um experimento de campo com a cultura da soja, realizado em área experimental da Universidade Estadual do Rio Grande do Sul, localizada no distrito de Três Vendas no município de Cachoeira do Sul - RS (2953' S e 53 00' W, altitude de 125 m), na região da depressão central do estado do Rio Grande do Sul. O clima da região é classificado por Köppen's como subtropical úmido, predominante na região Sul (ALVARES et al., 2014). O solo da área experimental foi classificado como Argissolo Vermelho distrófico típico (EMBRAPA, 2013).

A caracterização físico-hídrica do solo da área experimental foi realizada utilizando amostras de solo deformadas e indeformadas. As coletas, foram realizadas nas camadas de 0-10 cm, 10-30, $30-50 \mathrm{~cm}$ de profundidade do perfil do solo. Realizou-se análise de textura e curva característica de água no solo. Os principais resultados estão apresentados na Tabela 1.

Tabela 1 - Resultado da caracterização físico-hídrica do solo da área experimental. Cachoeira do Sul, 2017

\begin{tabular}{c|c|c|c|c|c|c}
\hline \multirow{2}{*}{ Camadas (m) } & \multicolumn{3}{|c|}{ Textura (\%) } & Umidade volumétrica $\left(\mathbf{c m}^{\mathbf{3}} \mathbf{c m}^{-3}\right)$ & \multirow{2}{*}{$\begin{array}{c}\text { Total de água } \\
\text { armazenada (mm) }\end{array}$} \\
\cline { 2 - 6 } & Areia & Silte & Argila & CC & PMP & 26,80 \\
\hline $0,0-0,10$ & 34,0 & 44,6 & 21,4 & 0,387 & 0,119 & 47,60 \\
\hline $0,10-0,30$ & 29,8 & 41,4 & 28,8 & 0,355 & 0,117 & 27,40 \\
\hline $0,30-0,50$ & 31,5 & 35,6 & 32,9 & 0,327 & 0,190 & \\
\hline
\end{tabular}

$\mathrm{O}$ experimento foi feito no delineamento experimental inteiramente casualizado com 12 repetições em parcelas (unidades experimentais) de 2,5 m x $10 \mathrm{~m}$. Os tratamentos constituíram das três cultivares de soja: Brasmax Garra IPRO (BMX GARRA), Nidera 4823 RR (NS 4823) e Nidera IPRO 5445 (NS 5445) cujos grupos de maturidade relativa variam entre 4,8 e 6,3 .

As cultivares foram semeadas no dia 19 de novembro de 2017, conforme indica o zoneamento agroclimático para a cultura no município. A semeadura foi realizada com um conjunto trator/semeadora, no sistema de plantio direto com espaçamento entrelinhas de cultivo de $0,50 \mathrm{~cm}$, respeitando a densidade de semeadura de cada cultivar. Os demais manejos e tratos culturais, seguiram as recomendações agronômicas para a cultura da soja.

A cultura foi irrigada sempre que o armazenamento de água do solo foi esgotado a $50 \%$ da capacidade total de água disponível, na camada de 0 a $30 \mathrm{~cm}$ de profundidade de perfil do solo. A irrigação foi realizada por meio de aspersores convencionais, instalados no espaçamento de $12 \times 12 \mathrm{~m}$ com uma taxa de aplicação de $12 \mathrm{~mm} \mathrm{~h}^{-1}$.

A determinação da necessidade de irrigação baseou-se na metodologia proposta por Allen et al. (1998). Para o cálculo da ETo pela equação FAO-Penman-Monteith, os dados meteorológicos de: temperatura do ar máxima e mínima $\left({ }^{\circ} \mathrm{C}\right)$, umidade relativa do ar máxima e mínima (\%), velocidade do vento $\left(\mathrm{ms}^{-1}\right)$, radiação solar $\left(\mathrm{KJ} \mathrm{m}^{-2} \mathrm{dia}^{-1}\right)$ e chuva $(\mathrm{mm})$, foram obtidas de uma estação meteorológica automática instalada próximo ao local de realização do experimento. Os valores de coeficiente de cultivo $(\mathrm{Kc})$ necessários para o cálculo da evapotranspiração da cultura $(\mathrm{Kc})$, basearam-se em adaptações do proposto por Allen et al. (1998), conforme apresentado na tabela 2. 
Tabela 2 - Coeficiente de cultivo para o cálculo da evapotranspiração da cultura (ETc). Cachoeira do Sul, 2017

\begin{tabular}{c|c|c}
\hline Valor do Kc & Período (em dias após a semeadura) & Estádio fenológico \\
\hline 0,3 & $1-19$ & $\mathrm{~V} 0-\mathrm{V} 4$ \\
\hline 0,6 & $20-29$ & $\mathrm{~V} 4-\mathrm{V} 6$ \\
\hline 0,8 & $30-50$ & $\mathrm{~V} 6-\mathrm{V} 14$ \\
\hline 1,1 & $51-91$ & $\mathrm{R} 1-\mathrm{R} 5$ \\
\hline 0,6 & $92-104$ & $\mathrm{R} 6-\mathrm{R} 7$ \\
\hline 0,3 & $104 \ldots$ & $\mathrm{R} 8$ \\
\hline
\end{tabular}

A partir da emergência das plantas de soja, realizaram-se duas vezes por semana, avaliações fenológicas em quatro plantas de cada cultivar. Utilizou-se a escala fenológica proposta pela Embrapa (2007).

No estádio fenológico de R1 (cultivar BMX Garra) e R2 (cultivares NS 4823 e NS 5445) realizaram-se avaliações morfológicas das plantas: área foliar e altura de plantas. Foram coletadas 3 plantas de cada parcela experimental e foram medidos o comprimento e a maior largura do folíolo central do trifólio de forma manual com o auxílio de uma régua.

A área foliar foi estimada pela equação 1, conforme sugere Richter et al (2014).

$$
A F=2,0185 X C X L
$$

Em que:

C: comprimento do folíolo central de cada trifólio $(\mathrm{cm})$;

L: largura do folíolo central de cada trifólio $(\mathrm{cm})$.

Após, foram calculados os índices de área foliar (IAF), conforme equação 2:

$$
I A F=\frac{A F}{A P}
$$

\section{Em que:}

AF: a área foliar $\left(\mathrm{cm}^{2}\right)$;

AP: é a área ocupada pela planta $\left(\mathrm{cm}^{2}\right)$.

Quando a cultura estava em estádio fenológico de maturidade fisiológica realizou-se a colheita manual das plantas da área central de cada parcela experimental. Para a análise dos componentes do rendimento: número de vagens planta ${ }^{-1}$; número de grãos vagem ${ }^{-1}$; peso de mil grãos (g) utilizou-se uma planta por parcela. Já, para a análise do rendimento de grãos $\left(\mathrm{kg} \mathrm{ha}^{-1}\right)$ utilizou-se todas as plantas colhidas. O peso de mil grãos e peso total dos grãos parcela ${ }^{-1}$ foram corrigidos para a umidade de $13 \%$ e peso total dos grãos parcela ${ }^{-1}$ foi extrapolado para $\mathrm{kg} \mathrm{ha}^{-1}$. 
As variáveis repostas: IAF, altura de plantas, número de vagens planta ${ }^{-1}$, número de grãos vagem ${ }^{-1}$, peso de mil grãos (g) e rendimento de grãos $\left(\mathrm{kg} \mathrm{ha}^{-1}\right)$ foram submetidas a análise da variância (teste $\mathrm{F}$ ) e o teste de média (teste de Tukey) por meio do software Sisvar, ao nível de 5\% de probabilidade de erro.

\section{Resultados e discussão}

Na Figura 1, apresenta-se o balanço hídrico da cultura a soja ao longo do ciclo de desenvolvimento.

Figura 1 - Balanço hídrico da cultura da soja. Cachoeira do Sul - RS, 2018

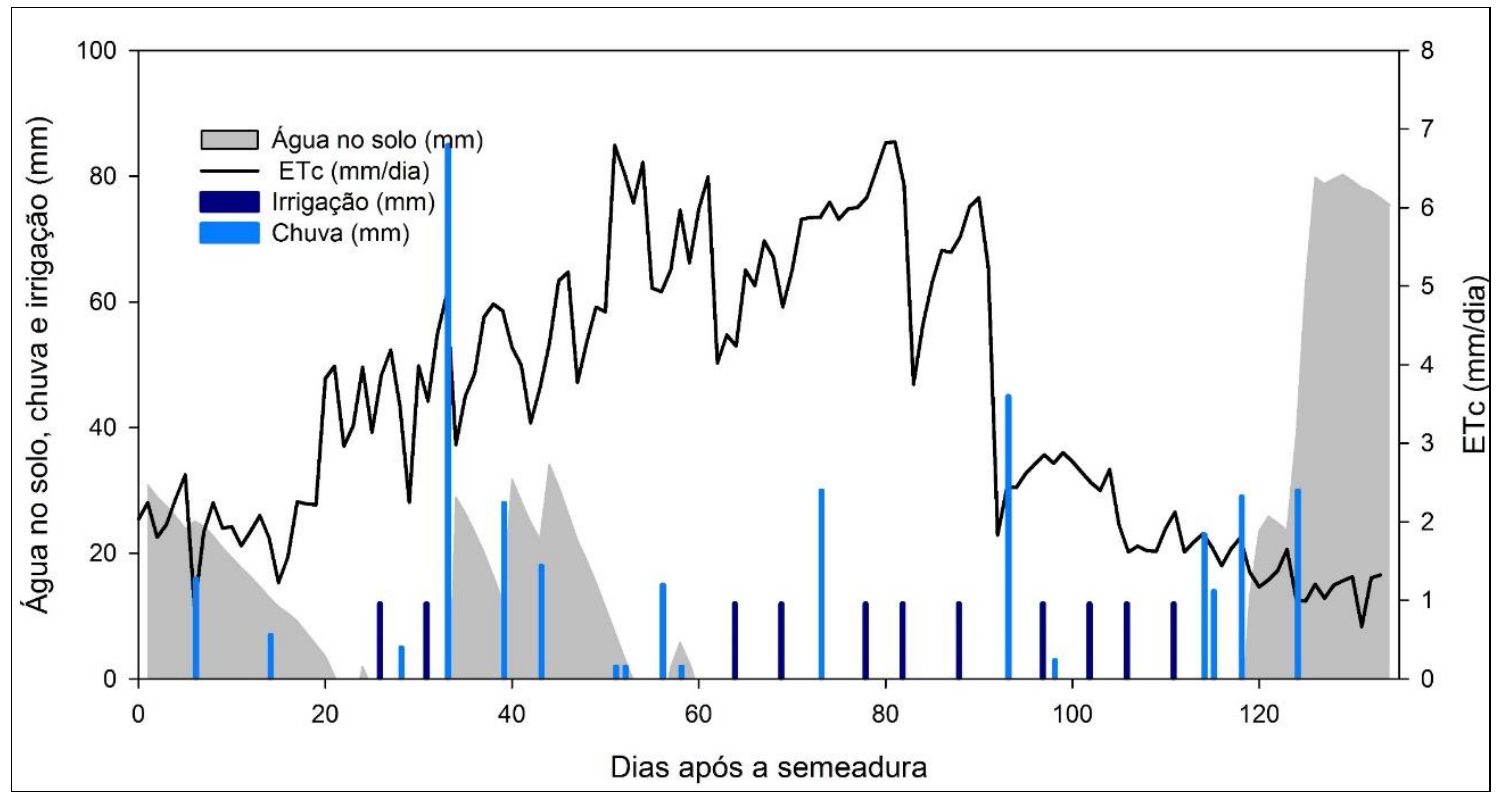

Observa-se um baixo volume de precipitações pluviométricas, especialmente, nos estágios de desenvolvimento da soja em que a ETc é elevada (45 a 90 dias), demandando de 5 irrigações suplementares nesse período. As irrigações suplementares se estendem a períodos mais avançado do ciclo de desenvolvimento da cultura (após 100 dias), em função do esgotamento de água no solo a limites muito baixos. Haja vista, aos reduzidos volumes de precipitação pluviométrica, que ao longo do ciclo da cultura somaram $354 \mathrm{~mm}$, enquanto que, a ETc acumulada foi de $467 \mathrm{~mm}$.

A água é um elemento imprescindível para a cultura, haja vista que uma planta de soja possui aproximadamente $90 \%$ de sua massa constituída de água que atua em processos fisiológicos e bioquímicos na planta. Principalmente nos períodos entre germinação-emergência e floração-enchimento de grãos. A deficiência hídrica ocorre quando a absorção de água é menor que a transpiração da planta, ou seja, conforme a água no solo diminui, a resistência radicular e do solo aumenta (ZANON et al., 2018). De acordo com Bergamaschi e Bergonci (2017), a planta apresentará sintomas de deficiência hídrica quando houver secamento do solo, absorção insuficiente de água em solos rasos (comum em soja de terras baixas), retenção osmótica de água (solos salinos) ou alta evapotranspiração (alta temperatura do ar e baixa umidade relativa do ar). A falta de água no solo afeta processos fisiológicos na planta, que utiliza mecanismos para retardar e/ou tolerar a desidratação. Alguns dos mecanismos são: o fechamento estomático, enrolamento das folhas, desenvolvimento de tricomas, redução da área foliar pela senescência de folhas (diminuindo a superfície exposta à luz solar) e regulação osmótica (STRECK, 2004; TAIZ e ZAIGER, 2013). 
$\mathrm{Na}$ tabela 3 está apresentado os resultados da análise da variância. Na qual, verifica-se diferenças estatísticas significativas entre as cultivares de soja avaliadas para todas as variáveis respostas, com exceção ao número de grãos vagem $^{-1}$ que apresentou valor médio de 2,15 (Tabela 4), corroborando com Zanon et al. (2018), que atribuí a uniformidade do melhoramento genético na busca de plantas com produção de, em média, dois a três grãos por legume. Entre diferentes situações de cultivo, o número de grãos por legume, dentre os demais componentes diretos, é o que apresenta menor variação (MUNDSTOCK e THOMAS, 2005).

Tabela 3 - Indicadores estatísticos para as variáveis respostas obtidas ao longo do ciclo de desenvolvimento da soja. Cachoeira do Sul (RS), 2018

\begin{tabular}{l|c|c|c}
\hline Variável resposta & CV (\%) & DMS & Pr>Fc \\
\hline Altura de plantas & 5,96 & 6,95 & $0,0004^{*}$ \\
\hline Índice de área foliar & 9,87 & 1,23 & $0,0003^{*}$ \\
\hline Vagem por planta & 9,19 & 54,41 & $0,027^{*}$ \\
\hline Grãos por vagem & 13,19 & 0,71 & $0,6840^{\text {ns }}$ \\
\hline Peso de mil grãos (g) & 1,66 & 7,68 & $0,0000^{*}$ \\
\hline Rendimento de grãos $\left(\mathrm{kg} \mathrm{ha}^{-1}\right)$ & 14,90 & 780,00 & $0,0000^{*}$ \\
\hline
\end{tabular}

*Significativo pelo teste $\mathrm{F}$ em nível de $5 \%$ de probabilidade de erro. ${ }^{\mathrm{ns}}$ não significativo pelo teste $\mathrm{F}$ em nível de $5 \%$ de probabilidade de erro.

$\mathrm{Na}$ tabela 4, é possível observar também, que a cultivar BMX Garra apresentou melhor desempenho agronômico em relação as demais cultivares.

Tabela 4 - Resultado das diferentes variáveis indicativas do desempenho agronômico da cultura da soja, observadas no ano agrícola 2017-18, em Cachoeira do Sul. Cachoeira do Sul (RS), 2018

\begin{tabular}{|c|c|c|c|}
\hline Variável resposta $*$ & BMX GARRA & NS 5445 & NS 4823 \\
\hline Altura de plantas & $57,33 \mathrm{a}$ & $38,50 \mathrm{~b}$ & $43,90 \mathrm{~b}$ \\
\hline Índice de área foliar & $7,09 \mathrm{a}$ & $3,95 \mathrm{~b}$ & $3,92 \mathrm{~b}$ \\
\hline Vagem por planta & 68,58 a & $53,08 \mathrm{~b}$ & $55,75 \mathrm{ab}$ \\
\hline Grãos por vagem & $2,27 \mathrm{a}$ & $2,11 \mathrm{a}$ & $2,08 \mathrm{a}$ \\
\hline Peso de mil grãos (g) & $216,02 \mathrm{a}$ & $181,10 \mathrm{~b}$ & $155,86 \mathrm{c}$ \\
\hline Rendimento de grãos $\left(\mathrm{kg} \mathrm{ha}^{-1}\right)$ & $4536,42 \mathrm{a}$ & $3803,01 \mathrm{~b}$ & $3273,07 \mathrm{c}$ \\
\hline
\end{tabular}

*Médias seguidas da mesma letra não apresentaram diferença estatística no teste de Tukey a 5\% de probabilidade de erro

Os resultados obtidos indicam que, para épocas de semeaduras entre outubro e novembro em Cachoeira do Sul, quanto maior o grupo de maturidade relativa, maior o IAF, haja vista que a cultivar BMX Garra apresentou IAF de 7,09, diferindo estatisticamente das demais cultivares que apresentaram IAF bem inferiores de 3,93 (valor médio). O IAF, observado para a cultivar BMX Garra, foi superior ao considerado ideal para um ambiente de alta produtividade. De acordo com Zanon et al. (2018), para atingir altas produtividades é necessário um IAF maior que 6,3. O IAF pode ser utilizado para representar a eficiência fotossintética, para análise do crescimento e, também, como fator condicionante da produtividade, pois através do IAF, é definida a capacidade do dossel em interceptar a radiação solar, converter em matéria seca através da 
fotossíntese, e determinar o potencial produtivo da cultura (HEIFFIG et al., 2006; SETIYONO et al., 2008; ZANON et al., 2015a; TAGLIAPIETRA et al., 2018).

O mesmo foi observado para a altura de plantas, em que a cultivar BMX Garra apresentou altura de 57,33 $\mathrm{cm}$ superior à das cultivares NS 5445 e NS 4823 que não apresentaram diferença estatística entre si, apresentando altura de $38,50 \mathrm{~cm}$ e 43,90 cm, respectivamente (Tabela 4). As variações na altura das plantas podem ser influenciadas por época de semeadura, espaçamento entre e dentro das fileiras, suprimento de umidade, temperatura, fertilidade do solo, resposta fotoperiódica da cultivar e outras condições do ambiente (ROCHA et al., 2012).

As variações na duração dos subperíodos e do ciclo total de desenvolvimento em função do grupo de maturidade relativa das cultivares estudadas pode ser observado na figura 2.

Figura 2 - Duração, em dias, dos subperíodos de emergência a floração plena (EM - R1) e de floração plena a maturidade fisiológica (R1- R8) e, do total do ciclo de desenvolvimento de três cultivares (NS 4823, NS 5445 e BMX

Garra). Cachoeira do Sul - RS, 2018

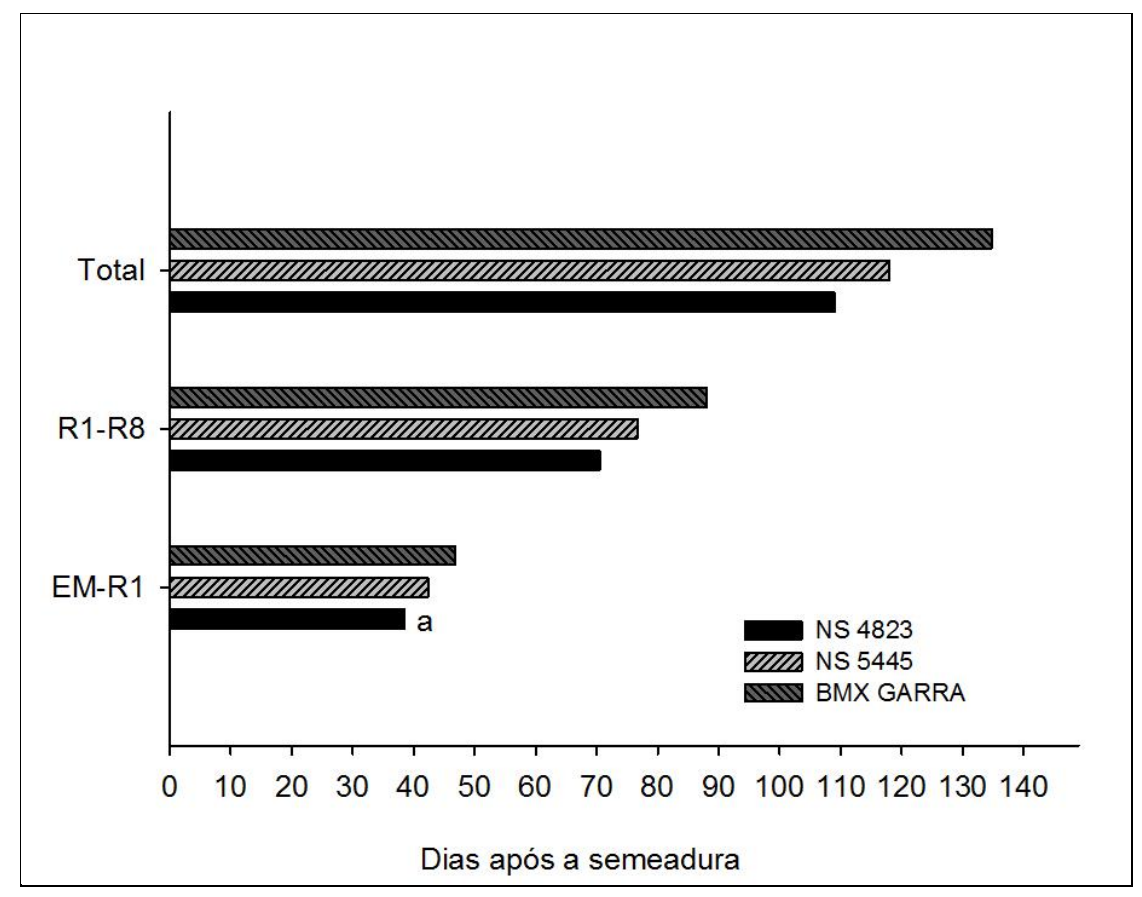

De acordo com Zanon et al. (2018), cultivares que apresentam grupos de maturação relativa entre 4,0 e 7,0 são indicadas para a Região Sul do Brasil, enquanto que as cultivares que apresentam grupos de maturação relativa entre 8,0 e 10,0 são indicadas para as regiões próximas da linha do Equador. Esta nova classificação de grupos de maturidade relativa, desenvolvida nos Estados Unidos, é baseada na resposta ao fotoperíodo, manejo e área geral de adaptação das cultivares de soja e permite representar de forma mais realísticas os fatores que afetam a duração do ciclo de desenvolvimento. Segundo Zanon (2015b) , a partir dessa nova classificação de cultivares através dos grupos de maturidade relativa, é maior a precisão na estimativa da duração do ciclo de desenvolvimento das cultivares de soja semeadas próximo à primeira quinzena de novembro. 
A maior duração do subperíodo emergência a floração para a cultivar BMX Garra em comparação as demais (Figura 2), resultou em maior IAF e altura de plantas e, estes, implicaram nos componentes de rendimento diretos (Tabela 4). De acordo com Navarro Junior e Costa (2002), são considerados componentes de rendimento diretos ou primários os componentes que, quando alterados, impactam diretamente sobre a produtividade de grãos, como por exemplo, número de vagens planta $^{-1}$; número de grãos vagem ${ }^{-1}$; peso de mil grãos. Os componentes considerados secundários ou indiretos são aqueles que afetam os componentes diretos. Dentre eles destaca-se a altura de plantas e índice de área foliar. A cultivar BMX Garra apresentou 68,58 vagens planta ${ }^{-1}$ diferindo estatisticamente da cultivar NS 5445, que apresentou 53,08 vagens planta $^{-1}$. A cultivar NS 4823 apresentou 55,75 vagens planta ${ }^{-1}$, não apresentando diferença estatística das demais cultivares.

Quanto ao peso de mil grãos (Tabela 4), as três cultivares analisadas apresentaram diferenças estatísticas. A cultivar NS 4823 apresentou peso de mil grãos de 155,86 g, a cultivar NS 5445 apresentou 181,10 g, e a cultivar BMX Garra apresentou 216,02 g. Segundo Weber (2017) o peso de mil grãos que maximiza a produtividade é $190 \mathrm{~g}$.

Analisando o rendimento de grãos (Tabela 4), todas as cultivares apresentaram diferenças estatísticas, sendo que a cultivar NS 4823 produziu 3273,07 $\mathrm{kg} \mathrm{ha}^{-1}$, a cultivar NS 5445 produziu 3803,01 $\mathrm{kg} \mathrm{ha}^{-1}$ e a cultivar BMX Garra, apresentou maior rendimento de 4536,42 $\mathrm{kg} \mathrm{ha}^{-1}$. De acordo com dados da Emater (2018), a produtividade média no município de Cachoeira do Sul no ano agrícola 2017/2018 foi de 2250,00 kg ha-1 ou seja, as três cultivares analisadas apresentaram rendimento superior ao contabilizado para a região, atribuído às irrigações suplementares aplicad as durante o ciclo (Figura 1).

\section{Conclusão}

A cultivar BMX Garra apresentou melhor desempenho agronômico e produtivo que as cultivares NS 5445 e NS 4823, para a época de semeadura preferencial no município de Cachoeira do Sul.

A irrigação suplementar foi necessária para a manutenção da disponibilidade hídrica no solo à cultura da soja, tendo em vista aos baixos volumes de precipitação pluviométrica durante o ciclo $(354 \mathrm{~mm})$ que foi inferior a evapotranspiração da cultura $(467 \mathrm{~mm})$, proporcionando uma maior produtividade das cultivares avaliadas em comparação à média do município de Cachoeira do Sul.

\section{Referências}

ALLEN, R. G.; PEREIRA; L. S.; RAES, D. Crop evapotranspiration. Guidelines for computing crop water requirements. Rome: Irrigation and Drainage Paper 56, 300p., FAO, 1998.

ALVARES, C. A.; STAPE, J. L.; SENTELHAS, P. C.; CONÇALVES, J. L. M.; SPAROVEK, G.; Köppen's Climate Classification Map for Brazil. Meteorologische Zeitschrift, v.22, No.6, 711-728p, January 2014.

BERGAMASCHI, H.; BERGONCI, J.I. As plantas e o clima: Princípios e aplicações. Guaíba: Agrolivros, 2017, $352 p$.

BOARD, J. E.; TAN, Q. Assimilatory capacity effects on soybean yeld components and pod number. Crop Science, Madison, v.35, n. 3, p. 846-851, May/June 1995.

CLICRBS. Plantação de Soja no Centro do RS Aumenta 35 mil Hectares e Bate Recorde. 2017 Gaúchazh. Disponível em: https://gauchazh.clicrbs.com.br/geral/noticia/2017/03/plantacao-de-soja-no-centro-do-rsaumenta-35-mil-hectares-e-bate-recorde-cj5wlwbiz1vnnxbj0w3mtpqtf.html> Acesso em: 25 de abril de 2018. 
EMPRESA DE ASSISTENCIA TECNICA E EXTENSAO RURAL DO RIO GRANDE DO SUL - EMATER/RS. 2018. Disponível em: https://gauchazh.clicrbs.com.br/economia/campo-e-lavoura/noticia/2018/04/infograficoconfira-as-diferencas-na-produtividade-da-soja-em-municipios-do-rs-cjfy09egk025k01tg8tsvl30y.html Acesso em: 25 de abril de 2018.

EMPRESA DE ASSISTENCIA TECNICA E EXTENSAO RURAL DO RIO GRANDE DO SUL - EMATER/RS. Safra de verão 2017/2018 - Estimativas iniciais de área e produção. Gerência de planejamento núcleo de informações e análises. Disponível em: http://www.emater.tche.br/site/arquivos pdf/safra/safraTabela 30082017.pdf Acesso em: 23 de agosto de 2018.

EMPRESA BRASILEIRA DE PESQUISA AGROPECUÁRIA - EMBRAPA. Ecofisiologia da soja. Circular Técnica, Paraná, 2007. ISSN 1516-7860. 9p.

EMPRESA BRASILEIRA DE PESQUISA AGROPECUÁRIA - EMBRAPA. Sistema brasileiro de classificação de solos. 3.ed. Brasília, 2013. 353p.

HEIFFIG, L. S. et al. Fechamento e índice de área foliar da cultura da soja em diferentes arranjos espaciais, v.65, p.285-295, 2006.

MATZENAUER, R.; BARNI, N. A.; MALUF, J. R. T. Estimativa do consumo relativo de água para a cultura da soja no Estado do Rio Grande do Sul. Ciência Rural, v.33, n.6, p.1013-1019, 2003.

MUNDSTOCK, C. M.; THOMAS, A. L. Soja: Fatores que afetam o crescimento e o rendimento de grãos. UFRGS, 2005. Disponível em: $\underline{w w w . u f r g s . b r / a g r o n o m i a / p l a n t a s / d e s t a q u e s / l i v r o ~ s o j a . p h p>~ A c e s s o ~ e m: ~} 25$ de agosto de 2018.

NAVARRO JR. H. M.; COSTA, J. A. Contribuição relativa dos componentes do rendimento para produção de grãos em soja. Pesquisa Agropecuária Brasileira, v.37, p.269-274,2002.

PIRES, J. L. F. et al. Métodos para a estimativa do potencial de rendimento da soja durante a ontogenia. Pesquisa Agropecuária Brasileira, v.40, p.337-344, 2005.

RICHTER, G.L.; JÚNIOR, A. Z.; STRECK, N. A.; GUEDES, J. V. C.; KRÄULICH, B.; ROCHA, J. E. M.; CERA, J. C. Estimativa da área de folhas de cultivares antigas e modernas de soja por método não destrutivo. 2014. Bragantia, Campinas, v. 73, n. 4, p.416-425.

ROCHA, R. S. et al. Desempenho agronômico de variedades e linhagens de soja em condições de baixa atitude em Teresina-P. Revista Ciência Agronômica, v.43, p.154-162, 2012.

SETIYONO, T. D. et al. Leaf área index simulation in soybean geown under near-optimal conditions. Field Crops Research, v. 108, p.82-92, 2008.

STRECK, N.A. Do we know how plants sense a drying soil?. Ciência Rural. v. 34, p.581-584. 2004.

STRECK, N.A.; PAULA, G.M.; CAMERA, C.; MENEZES, N.L.; LAGO, I. Estimativa do plastocrono em cultivares de soja. Bragantia, v.67, p.67-73, 2008.

TAGLIAPIETRA, E. L. et al. Optimum leaf área index to reach soybean yeld potential in subtropical environment. Agronomy Journal, v.110, p. 932-938, 2018.

TAIZ, L.; ZEIGER, E. Fisiologia vegetal. 5 ed. Porto Alegre: Artmed, 2013. 918p.

VERNETTI, F.J.; VERNETTI JUNIOR, F.J. Genética da soja: caracteres qualitativos e diversidade genética. Brasília: Embrapa Informação Tecnológica, 2009. 221p.

WEBER, P. S. Componentes de rendimento e grupo de maturidade relativa que influenciam o potencial de produtividade em soja. 2017. 34p. Trabalho de Conclusão de Curso (Graduação em Agronomia). Universidade Federal de Santa Maria, RS, 2017. 
ZANON, A. J. et al. Contribuição das ramificações e a evolução do índice de área foliar em cultivares modernas de soja. Bragantia, v.74, p.279-290, 2015a

ZANON, A. J. et al. Desenvolvimento de cultivares de soja em função do grupo de maturação e tipo de crescimento em terras altas e terras baixas. Bragantia, v.74, p.400-411, 2015b.

ZANON, A. J.; TAGLIAPIETRA, E. L.; BEXAIRA, K. P. JUNIOR, A. J. D.; WEBER, P. S.; SILVA, M. R.; CERA, J. C.; RICHTER, G. L. ROCHA, T. S. M.; STRECK, N.A. Ecofisiologia da soja- Visando altas produtividades. $1^{\circ} \mathrm{ed}$. Santa Maria: [n.s.], 2018. ISBN: 978-85-54856-14-4. 136p. 